\title{
ANÁLISE ERGONÔMICA DO TRABALHOCIRURGIÃO DENTISTA - DENTÍSTICA RESTAURADORA - ESTUDO DE CASO
}

\section{ERGONOMIC WORKING SURGEON DENTIST ANALYSIS - RESTORATIVE DENTISTRY - CASE STUDY}

\author{
Ari de Oliveira Maciel Júnior ${ }^{1}$; Rodrigo Eduardo Catai ${ }^{2}$ \\ ${ }^{1}$ Universidade Tecnológica Federal do Paraná - UTFPR - Curitiba - Brasil \\ arimacjr@hotmail.com \\ ${ }^{2}$ Universidade Tecnológica Federal do Paraná - UTFPR - Curitiba - Brasil \\ catai@utfpr.edu.br
}

\begin{abstract}
Resumo
O estudo de caso a seguir foi realizado na sala de atendimento de um consultório odontológico na cidade de Curitiba, Paraná. Utilizando-se dos conceitos da ergonomia, realizou-se a análise ergonômica no local de trabalho do cirurgião dentista e as influências das condições técnicas, ambientais e organizacionais na saúde, qualidade de vida e produtividade do profissional. A metodologia adotada foi baseada nos procedimentos da análise ergonômica do trabalho (conversas e observações sistemáticas) identificando as situações mais danosas à saúde do profissional. Realizou-se o diagnóstico ergonômico bem como recomendações ergonômicas para melhoramento do conforto nas atividades laborais do cirurgião dentista. As posições mais inconfortáveis encontradas foram: sobrecarga de atividades, as tarefas intra-bucais na parte superior da arcadadentária e as distâncias inadequadas dos equipamentos periféricos fotopolimerizador $e$ ultrassom. Desta forma, seguiram-se as definições ergonômicas e a norma regulamentadora (NR17), que visa a estabelecer padrões que favoreçam a adaptação das situações de trabalho às características psicofisiológicas dos trabalhadores, de modo a proporcionar um máximo de conforto, segurança e desempenho eficiente.
\end{abstract}

Palavras-chave:Ergonomia, Condições de Trabalho, Produtividade, Saúde Ocupacional.

\section{Introdução}

Já na época das cavernas o homem inconscientemente utilizava a ergonomia na preparação de armas e na construção de abrigos para sua sobrevivência. Todavia, por meados de 1840, na revolução industrial, é que se teve um avanço significativo nos métodos de trabalho e produção. Surgiu a necessidade de desenvolver técnicas e procedimentos que propiciassem a transição de fabricação artesanal para fabricação por máquinas e ao mesmo tempo minimizar os danos à saúde do trabalhador (IIDA, 2005). A ergonomia estende-se por diversas áreas e na odontologia tem fundamental importância nas atividades laborais do cirurgião dentista. 
O profissional de odontologia está exposto a vários riscos ocupacionais, a postura inadequada, os deslocamentos, torções do quadril ou pescoço e a posição de trabalho são fatores que podem, a curto e em longo prazo, causar Distúrbios Osteomusculares Relacionados ao Trabalho (DORT) prejudicando a produtividade.

Pretende-se, com um estudo de caso, avaliar as condições ergonômicas do posto de trabalho do cirurgião dentista, através dos princípios da Análise Ergonômica do Trabalho (AET), em um consultório odontológico, na cidade de Curitiba, Paraná. E, também, sugerir recomendações ergonômicas para reduzir o estresse físico e cognitivo. Além disso, evitar a ocorrência de patologias pertinentes ao exercício da odontologia alcançando uma produtividade mais significante, com melhor qualidade e maior conforto, tanto para o profissional quanto para o paciente (CASTRO; FIGLIOLI, 1999).

\section{Embasamento teórico}

O objetivo prático da ergonomia segundo Grandjean (1998) é a adaptação do posto de trabalho, dos instrumentos, das máquinas, dos horários, do meio ambiente às exigências do homem. A realização de tais objetivos, ao nível industrial, propicia uma facilidade do trabalho e um rendimento do esforço humano. Conforme Fialho e Santos (1995), o termo ergonomia significa, etimologicamente, o estudo das leis do trabalho.

A ergonomia é o estudo científico da relação entre o homem e seus meios, métodos e espaços de trabalho. Seu objetivo é elaborar, mediante a contribuição de diversas disciplinas científicas que a compõem, um corpo de conhecimentos que, dentro de uma perspectiva de aplicação, deve resultar em uma melhor adaptação ao homem dos meios tecnológicos, dos ambientes de trabalho e de vida (IEA, 2000). A adaptação da atividade ao trabalhador e não o trabalhador a atividade e a melhoria das práticas das tarefas com conforto, segurança e eficácia são alguns dos propósitos da análise ergonômica (GRANDJEAN, 1998).

Segundo Iida (2005), frequentemente os ergonomistas trabalham em domínios especializados, abordando certas características especificas do sistema, tais como: ergonomia física que se ocupa das características da anatomia humana, antropométrica, fisiologia e biomecânica; ergonomia cognitiva que trata dos processos mentais, como a percepção, memória, raciocínio e resposta motora; e, a ergonomia organizacional que se ocupa da otimização dos sistemas sócio técnicos, abrangendo as estruturas organizacionais, políticas e processos.

No Brasil, Moraes e Soares (1989), afirmam que a implantação da ergonomia ocorreu primeiramente junto às engenharias e ao desenho industrial. Tiveram como fundamento de suas 
especulações teóricas e aplicações práticas a adoção dos manuais de Grandjean (1998), Murrel (1975), Sanders e McCormick (1987) e Woodson (1981) apud Moraes e Soares (1989). Não se aplicava experimentos de laboratório, mas apenas se propunham algumas modificações com bases nos dados destas referências bibliográficas.

$\mathrm{Na}$ odontologia a ergonomia auxiliou no desenvolvimento de ferramentas, mobiliários e no melhoramento nas condições de trabalho dos cirurgiões dentistas. Atualmente os sofrimentos psíquicos e físicos são inerentes às atividades profissionais dos odontólogos, pois exercem sua profissão em um cenário de elevada concorrência profissional, na busca incessante por produtividade e redução de custos, gerando estresse bastante expressivo. A ergonomia odontológica pretende harmonizar o trabalho odontológico às particularidades antropométricas do corpo humano minimizando os riscos de ocorrência de patologias laborais e contribuindo para uma vida mais saudável (NOGUEIRA, 1983).

Segundo Rio e Rio (2000) aplicam-se os conceitos da ergonomia à prática odontológica com o objetivo de racionalizá-la, de acordo com as características do trabalho odontológico, possibilitando ao profissional evitar posturas e movimentos não produtivos e antianatômicos, evitando a fadiga e o desgaste desnecessário, produzindo mais e melhor e proporcionando maior conforto e segurança ao paciente. Ainda de acordo com estes autores, a ergonomia odontológica visa principalmente: propiciar maior conforto no trabalho; prevenir o estresse e a fadiga visual, física e psíquica; prevenir sintomas (dor, dormência, perda de força) e afecções musculoesqueléticas relacionadas ao trabalho; e prevenir o aparecimento de varizes dos membros inferiores.

Para Djerassi (1971 apud CASTRO; FIGLIOLI, 1999), a ergonomia aplicada à odontologia tem como objetivo obter meios e sistemas para diminuir o estresse físico e mental, prevenir as doenças ocupacionais, buscando uma produtividade mais expressiva. Para aplicação da ergonomia na odontologia é essencial projetar o layout do consultório odontológico com seus equipamentos, de forma a harmonizar a produtividade com o bem estar do profissional e do paciente. Segundo Iida (2005), o posto de trabalho é a configuração física do sistema homem-máquina-ambiente. É uma unidade produtiva envolvendo um homem e o equipamento que ele utiliza para realizar o trabalho, bem como o ambiente que o circunda.

Para Rio e Rio (2000), o posto de trabalho do cirurgião dentista é formado pelos seguintes elementos: cadeira, odontológica, mocho do dentista, refletor, equipo, unidade suctora (sugador e cuspideira) e unidade auxiliar. O posto de trabalho deverá ser avaliado sob uma ótica ergonômica, a fim de evitar patologias como os Distúrbios Osteomusculares Relacionados ao trabalho do cirurgião dentista (DORT). 
De acordo com Brasil (2003), entende-se por DORT como uma síndrome relacionada ao trabalho, caracterizada pela ocorrência de vários sintomas concomitantes ou não, tais como: dor, parestesia, sensação de peso, fadiga, geralmente nos membros superiores, mas podendo acometer também os membros inferiores. Estes sintomas resultam da combinação da sobrecarga das estruturas anatômicas do sistema osteomuscular com a falta de tempo para sua recuperação. A sobrecarga pode ocorrer seja pela utilização excessiva de determinados grupos musculares em movimentos repetitivos com ou sem exigência de esforço localizado, seja pela permanência de segmentos do corpo em determinadas posições por tempo prolongado, particularmente quando essas posições exigem esforço ou resistência das estruturas musculoesqueléticas contra a gravidade. A necessidade de concentração e atenção do trabalhador para realizar suas atividades e a tensão imposta pela organização do trabalho são fatores que interferem de forma significativa para a ocorrência do DORT.

Acredita-se que trabalhar com um auxiliar odontológico poderia minimizar a carga de trabalho do cirurgião dentista. Segundo Finkbeiner (2000) é rotina afirmar que executam o "trabalho a quatro mãos". No entanto, os relatos de estresse são evidentes, devido à utilização inadequada de equipamentos e técnicas pelo auxiliar odontológico. Há desconhecimento dos conceitos básicos do "trabalho a quatro mãos" evidenciadas pela falta de sincronia entre o cirurgião dentista e seu auxiliar. Os dentistas podem, ainda, serem observados realizando torções e virando-se para alcançar instrumentos ao seu lado. Se o assistente não está repondo constantemente todo o instrumental necessário e/ou os equipamentos, o "trabalho a quatro mãos” não está sendo praticado.

Neste cenário, segundo ANVISA (BRASIL, 2006) os profissionais da odontologia, estão expostos a riscos ocupacionais com a possibilidade de ocorrência de evento adverso. Os riscos mais frequentes a que estão sujeitos os profissionais que atuam na odontologia são:

- Os físicos: ruído, vibração, radiação ionizante e não ionizante, além de temperaturas extremas, iluminação deficiente ou excessiva, umidade e outros. São causadores desses riscos: caneta de alta rotação, compressor de ar, equipamento de RX, equipamento de laser, fotopolimerizador, autoclave, condicionador de ar, etc;

- Os químicos: poeiras, névoas, vapores, gases, mercúrio, produtos químicos em geral e outros. Os principais causadores desses riscos são: amalgamadores, desinfetantes químicos (álcool, glutaraldeído, hipoclorito de sódio, ácido pera cético, clorexidina, entre outros) e os gases medicinais (óxido nitroso e outros);

- Os ergonômicos: postura incorreta, ausência de um profissional auxiliar e/ou técnico, falta de capacitação do pessoal auxiliar, atenção e responsabilidade constantes, ausência de planejamento, ritmo excessivo, atos repetitivos, entre outros; 
- Os mecânicos ou de acidente: entre os mais frequentes, pode-se citar: espaço físico subdimensionado, arranjo físico inadequado, instrumental com defeito ou impróprio para o procedimento, perigo de incêndio ou explosão; edificação com defeitos; improvisações na instalação da rede hidráulica e elétrica; ausência de EPI e outros;

- Por ausência de conforto no ambiente de trabalho: sanitário em número insuficiente e sem separação por gênero e falta de produtos de higiene pessoal, como sabonete líquido e toalha descartável nos lavatórios, ausência de água potável para consumo, não fornecimento de uniformes, ausência de ambientes arejados para lazer e confortáveis para descanso, ausência de vestiários com armários para a guarda de pertences, falta de local apropriado para lanches ou refeições, falta de proteção contra chuva no caso de condições adversas como em comunidades remotas (ilhas e embarcações.), entre outros;

- Os biológicos: a probabilidade da ocorrência de um evento adverso em virtude da presença de um agente biológico. Sabe-se que as exposições ocupacionais a materiais biológicos potencialmente contaminados, constituem um sério risco aos profissionais da área da saúde nos seus locais de trabalho. Sendo que os acidentes envolvendo sangue e outros fluidos orgânicos correspondem às exposições mais frequentemente relatadas.

Rio e Rio (2000) sugerem as normas da International Standards Organization e a Federação Dentária Internacional (ISO-FDI) para sistematizar numericamente as posições a serem adotadas pelo cirurgião-dentista e seu auxiliar durante o atendimento odontológico. O esquema funciona como em um mostrador de relógio imaginário colocado sobre a cadeira odontológica, apresentando número 12 do relógio posicionado na cabeça do paciente e o número 6 nos pés do mesmo (Figura 1). A área delimitada pelo círculo A é chamada de zona de transferência onde esta a bandeja auxiliar e os instrumentos e pontas de equipo a serem transferidos a boca (campo operatório, bem como os mochos). Este círculo funcional permite aos dois operadores sentados, de modo mais ergonômico, o alcance às ferramentas necessárias à sua atividade sem imprimir esforço adicional às suas articulações, Rio e Rio (2000).

Figura 01 - Esquema gráfico (ISO/FDI) do posto odontológico 


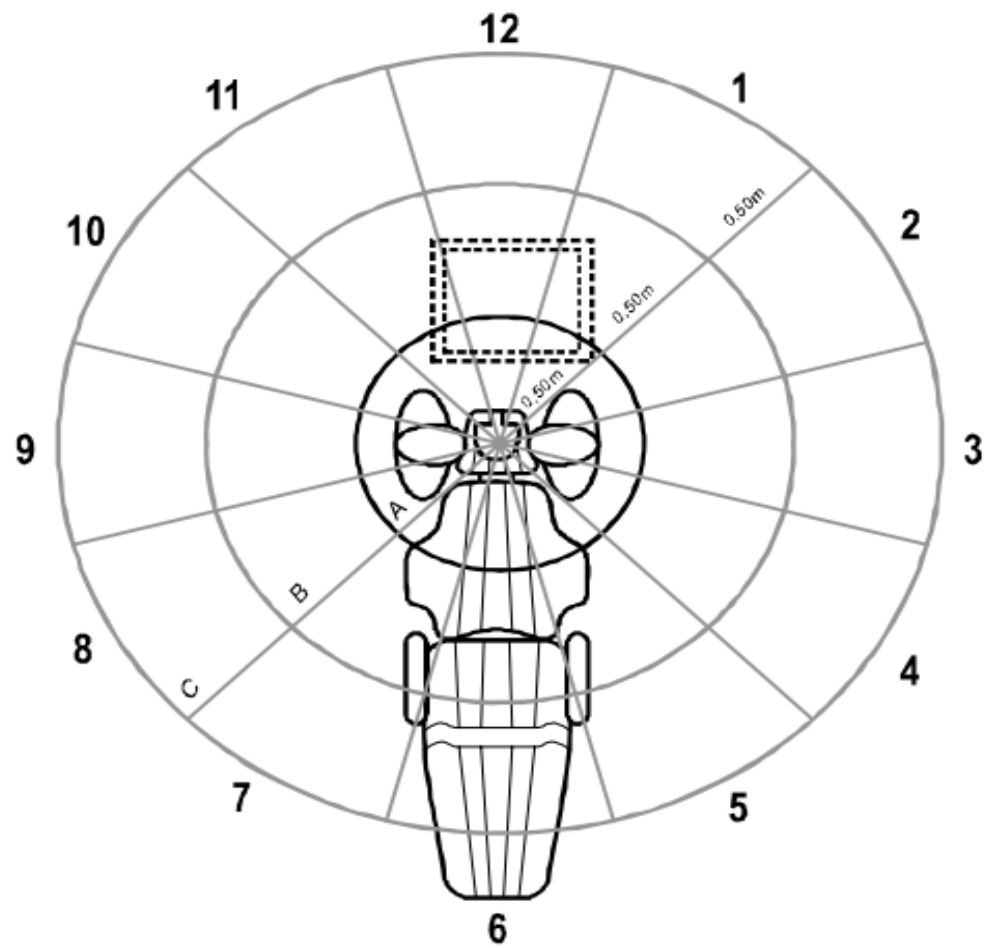

Fonte: (RIO; RIO, 2000).

Segundo Porto (1994), a posição pode ser determinada com base no posicionamento do profissional em relação a seu paciente. Normalmente, o profissional destro posiciona-se em 7, 9 ou 11 horas e o canhoto em 5, 3 e 1 horas.

Para o dentista destro, ainda conforme Porto (1994), a posição com as costas voltadas para as $7 \mathrm{~h}$ e com as pernas paralelas a cadeira é contra indicada por obrigar o mesmo a inclinar o corpo para $12 \mathrm{~h}$ à direita, causando prejuízos posturais. A posição $9 \mathrm{~h}$ é muito adotada por permitir trabalhar em visão direta, mesmo nas regiões de difícil acesso. Nessa posição a perna do dentista fica posicionada sob o encosto da cadeira do paciente e do lado direito do braço da mesma. Na posição 11 horas, por sua vez, o dentista fica atrás do paciente trabalhando com boa visão indireta, utilizando espelhos, nessa posição a perna esquerda do dentista fica sob o encosto da cadeira.

Para o dentista canhoto a posição muda, assim como a posição dos equipamentos, localizando-se à esquerda da cadeira do paciente. A posição 5 h não é a posição ideal, apresentando os mesmos inconvenientes da posição $7 \mathrm{~h}$. Sendo as mais indicadas as posições 3 e $1 \mathrm{~h}$, que correspondem às 9 e 11 h do dentista destro, respectivamente (PORTO,1994).

Vidal (2003) relata que a ergonomia é a disciplina que busca atender as demandas de transformação positiva da atividade laboral, isto mediante sua metodologia que é a Análise Ergonômica do Trabalho (AET). 
Segundo Iida (2005), a AET visa aplicar os conhecimentos de ergonomia para analisar, diagnosticar e corrigir uma situação real de trabalho. Ela foi desenvolvida por pesquisadores franceses e se constitui em um exemplo de ergonomia de correção. O método AET desdobra-se em cinco etapas:

- Análise da Demanda;

- Análise da Tarefa;

- Análise da Atividade;

- Diagnóstico;

- Recomendações Ergonômicas.

As três primeiras constituem a fase da análise e permitem realizar o diagnostico para formular as recomendações ergonômicas (Iida, 2005).

\section{Fundamentos metodológicos}

Este estudo é caracterizado como pesquisa descritiva do tipo estudo de caso, pois segundo Moraes e Mont'Alvão (1998), neste tipo de trabalho o pesquisador procura conhecer e interpretar a realidade, sem nela interferir para modificá-la, interessa-se em descobrir e observar fenômenos e procura descrevê-los, classificá-los e interpretá-los.

Os instrumentos utilizados foram às observações livres ou sistemáticas, conversa ou entrevista e fotografias, na aplicação da Análise Ergonômica do Trabalho (AET), em que foram abordados: análise da demanda, análise da tarefa, análise da atividade, diagnóstico e as recomendações ergonômicas.

\section{O estudo de caso: posto de trabalho do profissional de dentística restauradora.}

\subsection{Análise da demanda}

Escolheu-se o posto de trabalho de um cirurgião dentista do sexo feminino, destro, clinica geral, especialista em Dentística Restauradora, na cidade de Curitiba - Paraná e que atua na profissão a mais de 15 anos. A carga horária diária não segue um padrão, ela é determinada conforme são realizados os agendamentos das consultas.

Figura 2: ConsultórioOdontológico (Demanda) 


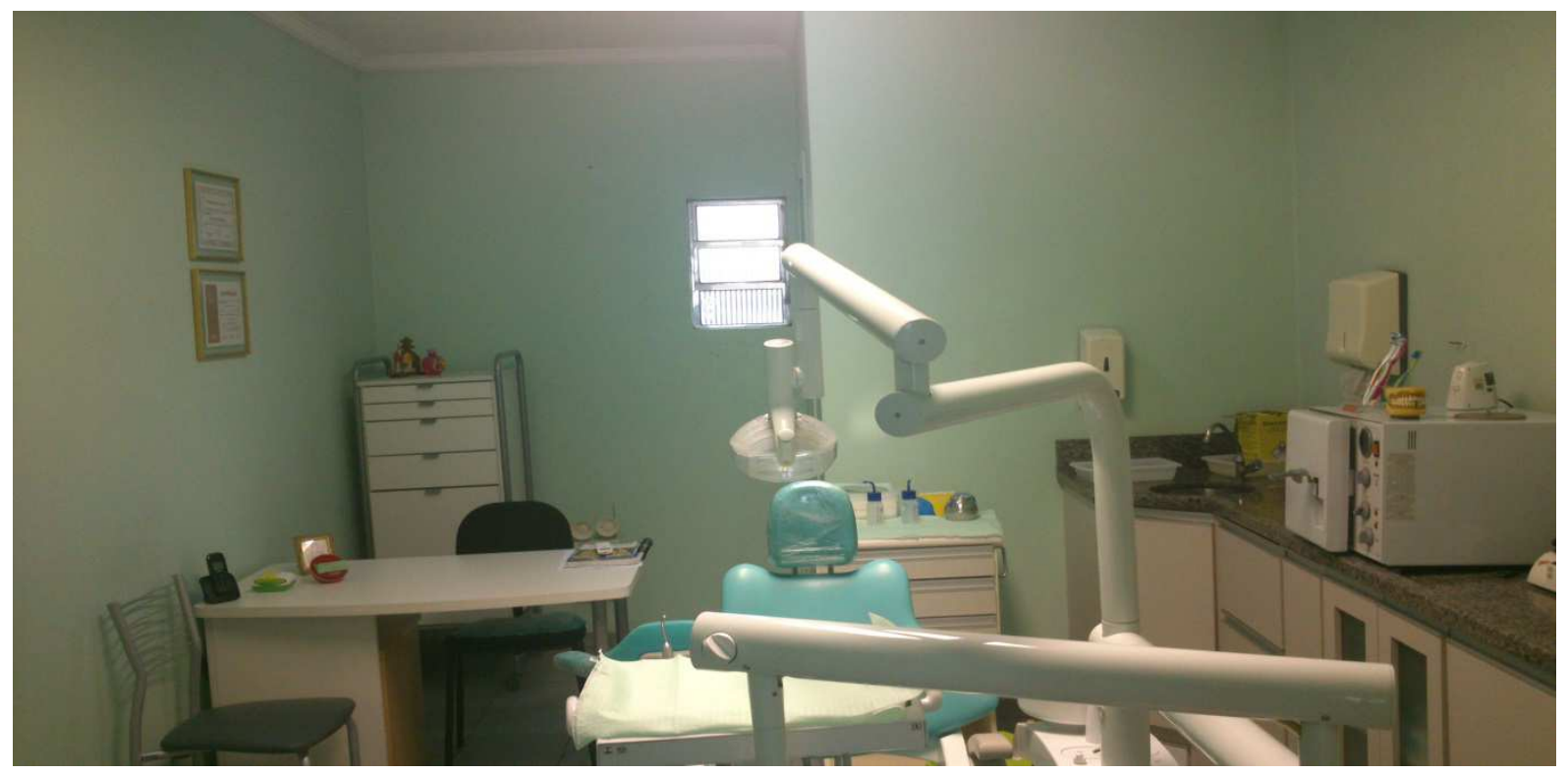

Fonte: Autoria própria (2015).

Conforme descrevem Fialho e Santos (1995), pode-se classificar a análise da demanda em três grupos:

1. As demandas formuladas com o objetivo de buscar recomendações ergonômicas para implantação de um novo sistema de produção;

2. As demandas formuladas com o objetivo de resolver as disfunções do sistema de produção já implantado, relativas aos comportamentos do homem, da máquina, ou ainda da organização, que se traduzem em problemas ergonômicos (sofrimento físico e mental, doenças profissionais, acidentes, incidentes, absenteísmo, baixa produtividade, qualidade insuficiente, etc.). Neste caso, a partir de uma análise ergonômica da situação existente, pode-se realizar o diagnóstico dessas disfunções e propor uma série de recomendações.

3. As demandas formuladas com o objetivo de identificar as novas condicionantes de produção, numa determinada situação de trabalho, introduzidas pela implantação de uma nova tecnologia ou novos modos organizacionais.

O presente estudo é caracterizado pelo segundo grupo citado. A demanda neste caso está associada ao acúmulo de tarefas, pois a cirurgiã dentista destra trabalha sozinha, ou seja, sem auxiliar. Fica evidente a sobrecarga de trabalho: a limpeza geral do consultório, agendamentos, esterilização, compra de materiais e os procedimentos odontológicos convergem em um único recurso. No consultório ocorrem diversos movimentos ou deslocamentos, como a ida até o armário e gaveteiros para selecionar materiais, deslocamento com o mocho para ativar e desativar o sugador e mudanças na posição do refletor conforme o procedimento. Preocupa-se mais com o bem estar do paciente e com o êxito dos tratamentos odontológicos e menos com as práticas ergonômicas.

Vidal (2003) afirma que a sobrecarga de trabalho resulta das exigências sobre o individuo, 
no decorrer de sua atividade de trabalho, que pesam sobre o desempenho. Uma atividade normal, bem dimensionada e coerente com as capacidades e limitações da pessoa não implicam em sobrecarga de trabalho. Quando, entretanto, as demandas do sistema estão acima da capacidade de desempenho possível da pessoa, ocorre à situação de sobrecarga e se torna necessária a atuação da ergonomia.

\subsection{Análise da tarefa}

Iida (2005) descreve que tarefa é um conjunto de objetivos prescritos, que os trabalhadores devem cumprir. Ela corresponde a um planejamento do trabalho e pode estar contida em documentos formais, como a descrição de cargos. Fialho e Santos (1995), afirmam que a análise da tarefa parte das condições dentro das quais o trabalhador desenvolve suas atividades de trabalho.

$\mathrm{Na}$ especialidade dentística restauradora reabilita-se a forma e a função dos dentes acometidos por cárie ou trauma, por meio de restauração e reconstrução. Além disso, atua na modificação do contorno dos dentes para ajustes estéticos. A resina é a mais utilizada, pois é da mesma cor do dente. Sendo assim, o principal objetivo do tratamento odontológico é a conservação do elemento dentário proporcionando sua reabilitação funcional e sua estética.

Inicialmente realiza-se a anamnese, ou seja, interrogatório ao paciente procurando detalhes que possam auxiliar no diagnóstico. Em seguida, quando necessário, preparam-se os métodos anestésicos (tópicos e infiltrativos) para a remoção do tecido cariado com instrumentos de alta rotação, baixa rotação e curetas. Feita a remoção completa do tecido cariado, restaura-se a cavidade dentária com material especifico eleito pelo profissional. Caso o material indicado for à resina composta utiliza-se o fotopolimerizador para concluir a restauração. Por fỉm, é feito o acabamento e polimento.

Para auxiliar tecnicamente suas tarefas o cirurgião dentista utiliza alguns equipamentos, tais como: cadeira odontológica, mocho (banco), equipo, mesa clínica auxiliar, canetas de alta e baixa rotação, unidade auxiliar, equipamento de raio $\mathrm{X}$, ultrassom, fotopolimerizador e equipamentos de proteção individual (EPIs). Ao ser questionada sobre a influência dos equipamentos nas tarefas, a cirurgiã-dentista afirmou que todos estavam em boas condições de uso e ajustados de forma mais confortável e produtiva possível. Entretanto, em alguns casos abandonam-se os preceitos ergonômicos e optam pela praticidade do momento. Exemplificando, podem-se citar casos de pacientes que possuem movimentos limitados do conjunto pescoço-cabeça, o qual a profissional adapta-se a esta situação.

Para Barros (1993), as dimensões do ambiente físico devem proporcionar conforto tanto 
para os profissionais como para os pacientes, e para um "trabalho a quatro mãos", a área mínima ideal deve ser de $9 \mathrm{~m}^{2}$ do tipo 3 metros por 3 metros. No consultório odontológico em estudo tem-se uma área de $10 \mathrm{~m}^{2}(2,5 \mathrm{~m} \times 4 \mathrm{~m})$, ou seja, tamanho adequado para a realização das tarefas, conforme layout da Figura 3.

Figura 3: Layout Posto de Trabalho Consultório Odontológico

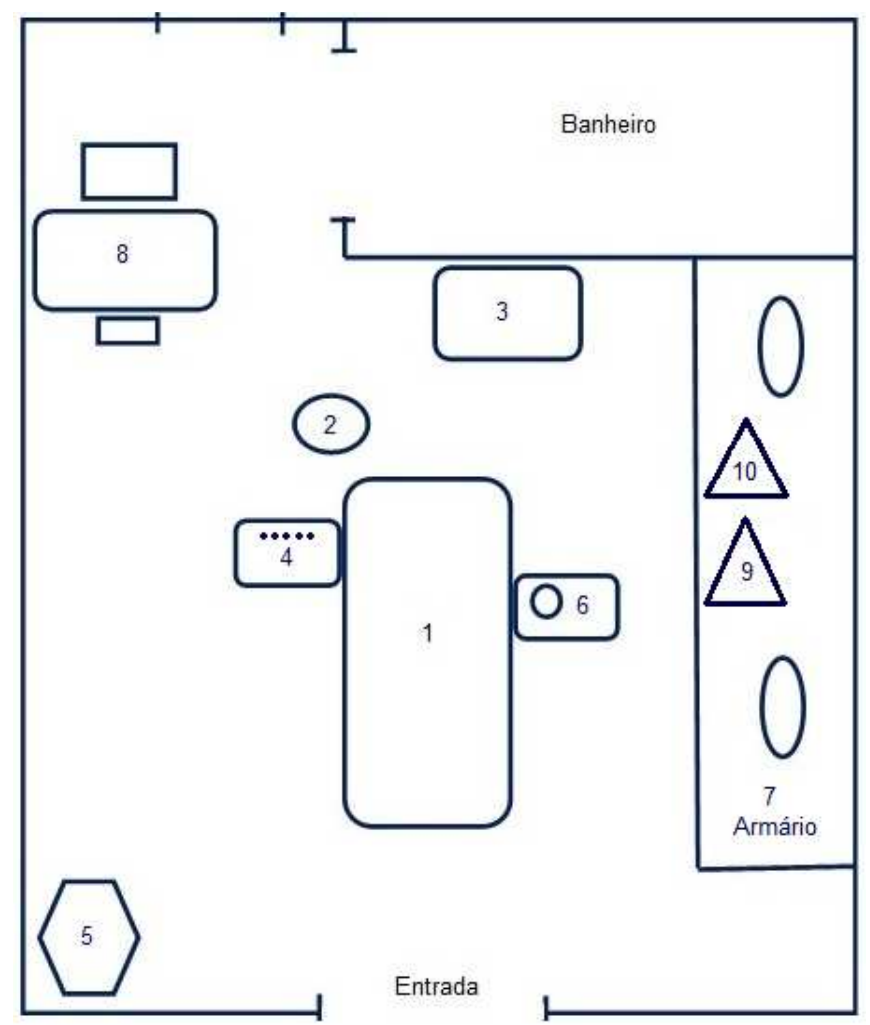

Nota: 1 - Cadeira; 2 - Mocho; 3 - Mesa clínica auxiliar; 4 - Equipo; 5 - Aparelho de raio X; 6 - Unidade auxiliar (cuspideira); 7 - Armário; 8 - Mesa de escritório; 9 - Fotopolimerizador; 10 - Ultrassom.

Fonte: Autoria própria (2015).

\subsection{Análise da atividade}

Iida (2005) afirma que dentro da AET pode-se entender atividade como o comportamento do trabalhador na realização de uma tarefa, ou seja, a partir da prescrição da tarefa a análise da atividade consistirá em observar a maneira como o profissional procede para atingir as metas estabelecidas. Em muitos casos a atividade é reconhecida como as possíveis ações que o trabalhador toma diante do trabalho. Essas ações, por sua vez, são consideradas como resultado do processo de adaptação entre os diversos fatores envolvidos no posto de trabalho.

Para Moraes e Mont' Alvão (1998) por atividade observam-se os seguintes comportamentos:

- Tomada de informações (observado pelos movimentos de cabeça e pés);

- Gestos de acionamento; 
- Posturas assumidas em função da tomada de informações e gestos;

- Comunicações (gestuais ou verbais);

- Deslocamentos;

- Movimentação manual de materiais.

Para Pietrobon e Regis Filho (2006), a profissão do cirurgião-dentista tem como tarefa uma rotina diária de trabalho que exige, dos membros superiores e estruturas contíguas, uma frequência de movimentos repetitivos padrão, devido suas atividades clínica. Com o passar do tempo, o exercício da profissão de cirurgião dentista poderá influenciar também nas movimentações e posturas fora do ambiente de trabalho.

Neste estudo, na maioria dos tratamentos a posição adotada pelo cirurgião dentista é a sentada, isto é, levemente inclinada em atenção ao paciente. A posição sentada adotada é alternada entre 9 horas e 11 horas conforme ISO-FDI. A Figura 4 ilustra essa posição.

Figura 4: Posição 9 horas (ISO-FDI)

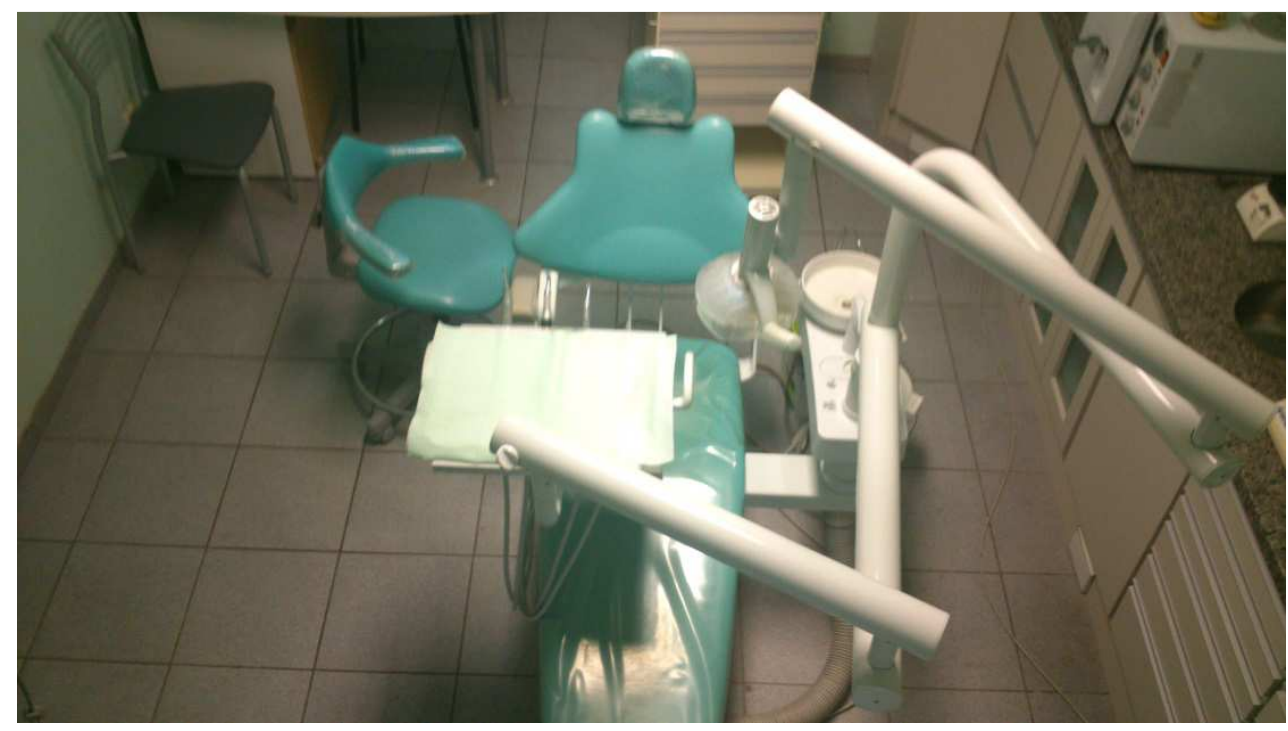

Fonte: Autoria própria (2015).

Através das técnicas da dentística restauradora, percebe-se a redução de esforços e posturas desnecessárias para realização dos tratamentos e a preocupação de não causar medo/dor nos pacientes. Entretanto, as tarefas intra-bucais na parte superior da boca obrigam o profissional a uma posição incomoda. Porém, a agilidade e a precisão no manuseio dos instrumentos condicionam os movimentos e minimizam os esforços lombares, da musculatura cervical, do pescoço, de punhos e das pernas, afastando, assim, a possibilidade de ocorrência de LER/DORT e propiciando razoável conforto na sua atividade profissional.

As condições ambientais no consultório odontológico são aceitáveis para o desenvolvimento das atividades, pois se percebe agradável temperatura (entre $20^{\circ} \mathrm{C}$ e $23^{\circ} \mathrm{C}$ ) devido ao sistema de 
condicionamento do ar. Por segurança, os cirurgiões dentistas necessitam utilizar vestimenta e EPIs adequados em suas atividades, podendo causar desconfortos térmicos. A iluminação é condizente com a altura do plano de trabalho (aproximadamente 500 lux), e quando necessário utiliza-se o refletor odontológico. Identificam-se ruídos intermitentes e incômodos, variando de $82 \mathrm{~dB}(\mathrm{~A})$ à 92 $\mathrm{dB}(\mathrm{A})$, devido à utilização das canetas de alta rotação, sugador e acionamento esporádico do compressor de ar. Constata-se também risco biológico, pois o cirurgião dentista na maioria do tempo está em contato com plano de trabalho eivado e os instrumentos de alta rotação originam vaporização, deslocando partículas e contaminantes em suspensão. Entende-se que esta condição pode ser nociva às atividades profissionais.

$\mathrm{Na}$ organização das atividades, para otimizar o tempo de cada atendimento, todos os instrumentos, equipamentos e materiais utilizados são previamente esterilizados e posicionados no raio de ação, conforme o tipo de tratamento. Todavia, o fotopolimerizador, o ultrassom e o raio $\mathrm{X}$ (Figura 5) estão posicionados um pouco além deste raio de ação. Na utilização do raio X, o procedimento é realizado com o cirurgião dentista em pé, paciente sentado e com equipamento de proteção individual (EPI). A profissional dentista deste estudo trabalha sozinha, desta forma, durante a jornada de trabalho percebem-se movimentações constantes até e a mesa de escritório para atendimento telefônico, marcação de consultas e manuseio das fichas dos pacientes (Figura 6).

Destacam-se também os deslocamentos necessários para destinação adequada do lixo odontológico que são coletados por empresa especializada. Em média atende-se de quatro a cinco pacientes por dia, o tempo varia conforme o tratamento, sendo necessária a preparação, lavagem e esterilização dos instrumentos para cada paciente. No final da jornada de trabalho, queixa-se de formigamentos passageiros, dores lombares, dores nos punhos e certa irritabilidade.

Figura 5: Raio-x, fotopolimerizador e ultrassom 

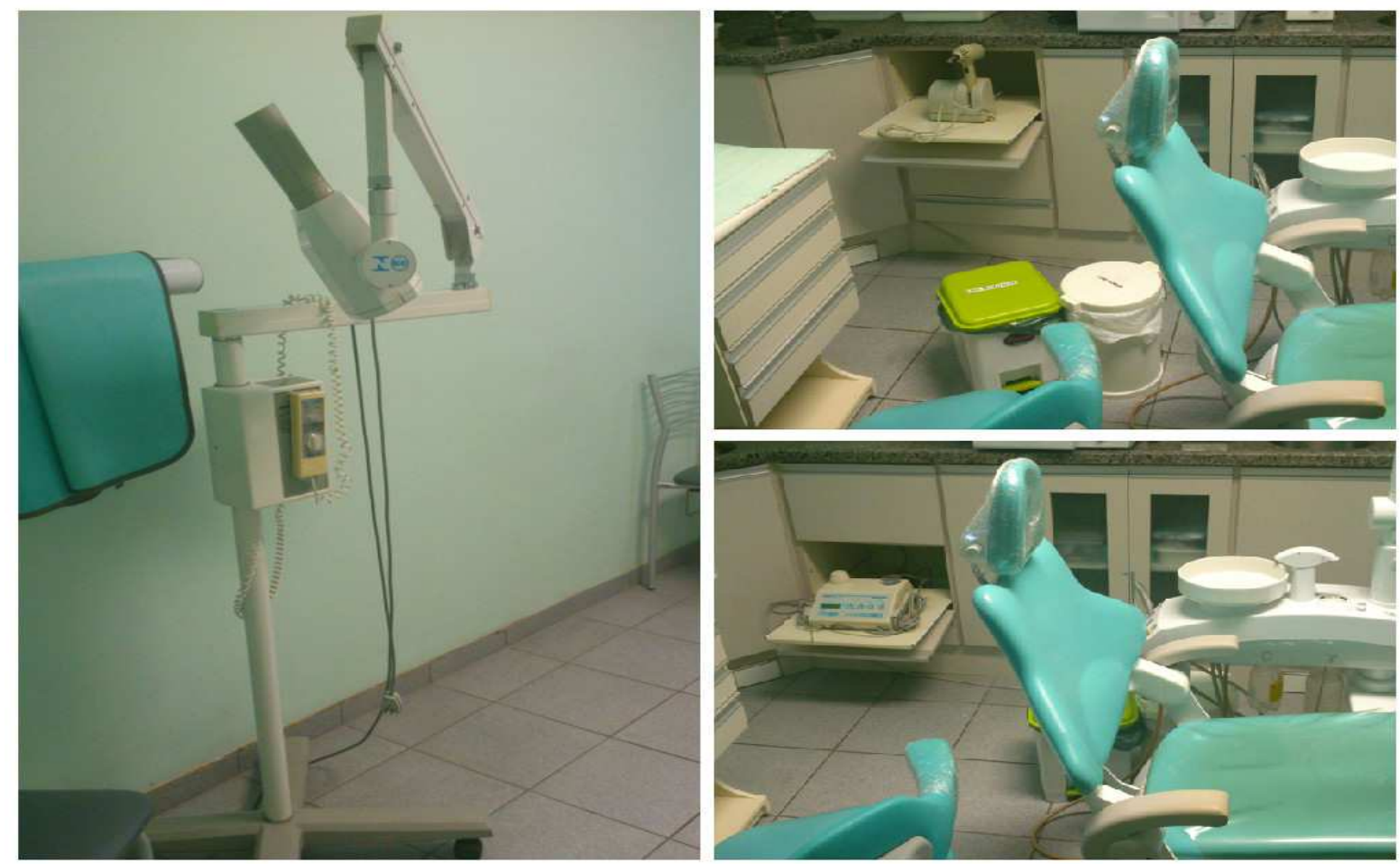

Fonte: Autoria própria (2015).

Figura 6: Organização do trabalho sem auxiliar odontológico
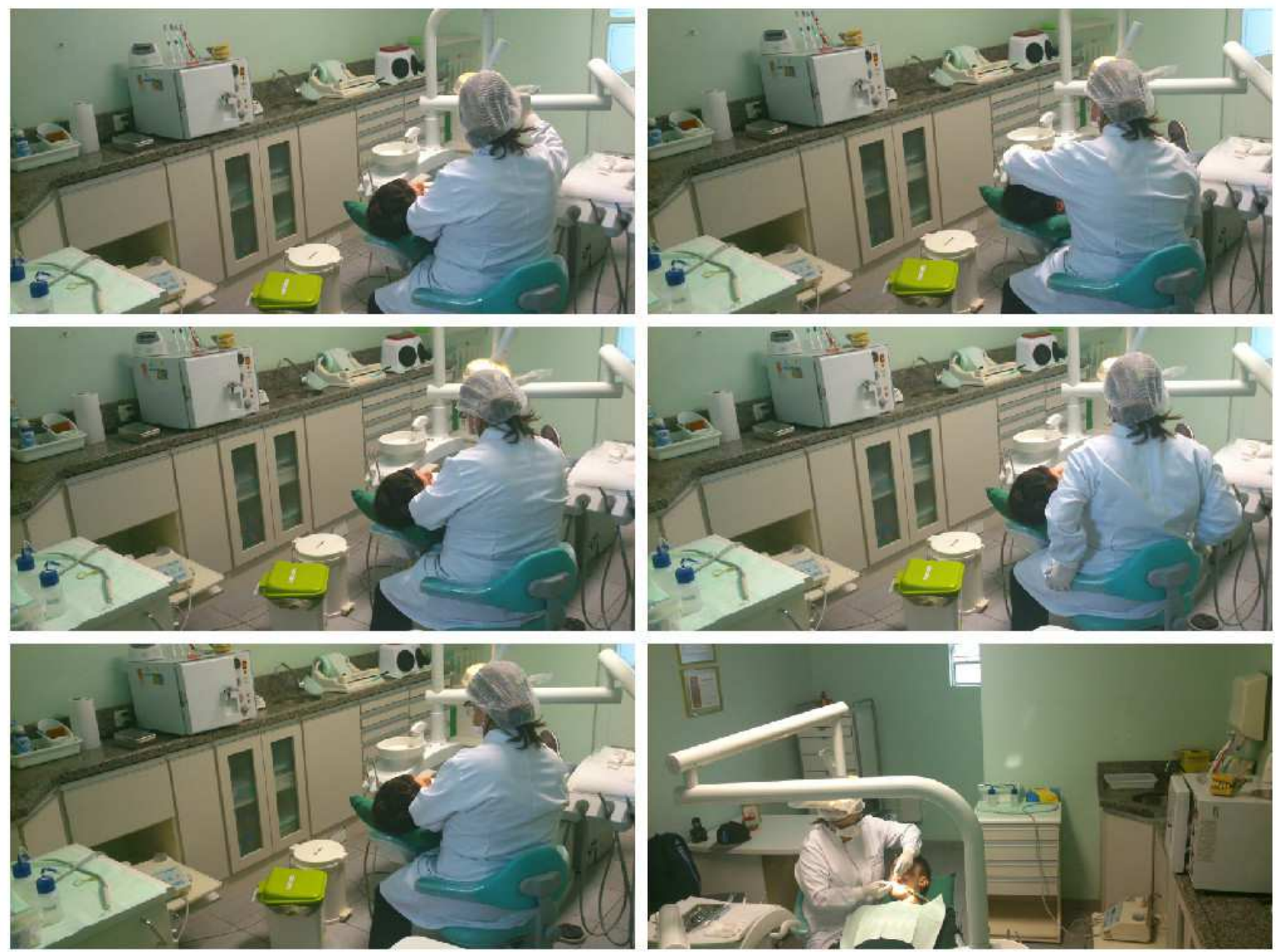

Fonte: Autoria própria (2015). 


\subsection{Diagnóstico}

Para Guerin (2001), o diagnóstico aponta os fatores a serem considerados para permitir uma transformação da situação de trabalho.

A carga excessiva de demandas sobre o cirurgião dentista estava evidente, pois o mesmo deveria contar com ajuda de um auxiliar odontológico (Figura 6). Esta sobrecarga afeta diretamente sua organização do tempo, desempenho e produtividade. Contudo, torna-se inviável a contratação de um auxiliar odontológico devido às questões trabalhistas e econômicas. Todos os equipamentos e instrumentos observados estão calibrados, ajustados e em boas condições de uso, facilitando o trabalho nos tratamentos triviais e de pacientes especiais com limitações do conjunto pescoçocabeça. Os movimentos dos membros superiores e sistema cervical são frequentes durante toda a atividade profissional. Pela complexidade de alguns tratamentos, o profissional foca no elemento dentário e é flagrado em posições e posturas estáticas com tensão muscular, que podem causar fadigas e dores. São conhecidas às práticas ergonômicas, porém não são aplicadas em todo o tempo.

Atua-se num ambiente bem dimensionado, com bom iluminamento (acima de 500 lux) e índice de temperatura efetiva entre $20^{\circ}$ e $23^{\circ} \mathrm{C}$, conforme NR-17 (MTE, 2015). Com a ausência do auxiliar odontológico alternam-se as posições sentadas entre 9 horas, 11 horas e em casos mais específicos 7 horas. Com relação ao alcance dos equipamentos, deve-se revisar o posicionamento do ultrassom e do fotopolimerizador, pois para utilizá-los levanta-se do mocho para ativá-los e desativá-los. Os deslocamentos são constantes para lavagem e esterilização dos instrumentos, procedimentos no raio $\mathrm{X}$, atendimento telefônico, consultas às fichas dos pacientes e à correta destinação dos resíduos após cada tratamento.

\subsection{Recomendações ergonômicas}

Para se evitar problemas de saúde ocupacional, melhoramento do conforto no ambiente de trabalho e prejudicar a produtividade nas atividades do cirurgião dentista em seu consultório odontológico sugerem-se:

- Estudo de viabilização para contratação de auxiliar odontológico capacitado;

- Manutenção periódica dos instrumentos e equipamentos;

- Antes dos tratamentos, deixar previamente posicionado e selecionado todos os equipamentos e materiais, a fim de evitar deslocamentos para fora do raio de alcance.

- Usufruir sempre do dispositivo de giro do mocho e regulagem do apoio lombar evitando rotacionar a coluna. 
- Para evitar problemas de circulação, regular a altura do mocho de forma que as pernas formem um ângulo de $90^{\circ}$.

- Fazer pausas sempre que possível e realizando alongamentos;

- Investir em novos equipamentos que facilitem a realização de determinadas tarefas. Exemplo: substituição do fotopolimerizador com fio por um sem fio, caneta de alta rotação com fibra óptica, etc.

- Reposicionar o ultrassom para dentro do raio de ação;

- Utilizar EPIs e vestimentas adequadas.

- Agendar os tratamentos mais desgastantes de modo evitar e execução dos mesmos em sequência.

- Práticas esportivas (ginástica, natação, etc.).

\subsection{Observações finais}

A Análise Ergonômica do Trabalho no consultório odontológico em estudo apontou pequenos desvios de ergonomia. Estes desvios são contrários ao conforto no ambiente de trabalho, prejudicam a produtividade e podem causar fadigas musculares, formigamentos, dores lombares, dores nos punhos e irritabilidade.

O excesso de atividades mostra-se como maior ofensor, influenciando na organização de tempo e desempenho das atividades. Identificam-se em menor grau desleixos posturais, devido à dinâmica dos tratamentos, esquece-se da ergonomia, pois se prioriza o êxito dos tratamentos nos pacientes. Alguns equipamentos, fora do raio de ação, reproduzem maior utilização do sistema cervical e membros superiores e inferiores, que poderiam ser reposicionados.

Observou-se também, através deste estudo, uma consciência prevencionista e gestão de riscos ergonômicos, que devem ser seguidos pelo cirurgião dentista, pois a análise ergonômica do trabalho é determinante para evitar a ocorrência de DORT/LER e outras patologias decorrentes desta atividade profissional.

\section{Conclusões}

Por intermédio da Análise Ergonômica do Trabalho (AET), investigou-se as condições do posto de trabalho de uma cirurgiã dentista, com especialidade em dentística restauradora. Objetivou-se formar um panorama desta atividade profissional, propondo recomendações ergonômicas, desenvolvimento de diagnósticos e, por conseguinte ajustes ergonômicos.

A exposição aos riscos ocupacionais torna-se perceptível ao investigar as particularidades da 
organização de trabalho desta profissional. Descreve-se as atividades profissionais por ela desempenhadas como: privativa, detalhista, e estressante.

Apesar de lidar diariamente com aspectos inconvenientes como a dor, o medo, a exatidão dos procedimentos, e a busca pela redução dos custos, a profissional estudada demonstra contentamento ao realizar com êxito os procedimentos que aliviam temores, angústias e dores dos pacientes, bem como garantem os aspectos estéticos e funcionais. Neste contexto, existe a possibilidade de estudos futuros, como aumentar o número da amostra (profissionais) ou análises que envolvam a identificação de fatores psíquicos que envolvam o processo de organização do trabalho.

\begin{abstract}
The following case study was conducted in answering a dental office room in the city of Curitiba, Paraná. Using the concepts of ergonomics, there was the ergonomic analysis in the dentist's workplace and the influences of technical, environmental and organizational conditions in the health, quality of life and productivity of the professional. The methodology adopted was based on the procedures of the ergonomic analysis of work (conversations, systematic observations) identifying the most harmful situations health professional. We carried out the ergonomic diagnosis and ergonomic recommendations for improving comfort in the work activities of the dentist. The most uncomfortable positions were: overhead activities, intra-oral tasks on top of the dental arch and inadequate distances peripheral equipment (curing light, ultrasound, amalgamator machine). In this way, followed by the ergonomic concepts and the regulatory standard (NR-17), which aims to establish parameters that allow the adjustment of working conditions to the psycho physiological characteristics of workers, in order to provide maximum comfort, safety and performance efficient. Keywords: Ergonomics, Working Conditions, Productivity, Occupational Health.
\end{abstract}

\title{
Referências
}

BRASIL. Ministério da Saúde. Agência Nacional de Vigilância Sanitária. Serviços Odontológicos: prevenção e controle de riscos. Brasília: Ministério da Saúde, 2006.

BRASIL. Instrução Normativa INSS/DC Nº 98 - DE 05 DE DEZEMBRO DE 2003- DOU de 10/12/2003. Disponível em: <http://www3.dataprev.gov.br/sislex/imagens/paginas/38/inss-dc/2003/anexos/IN-DC-98-ANEXO.htm >. Acesso em: 12 fev.2015.

BARROS, O. B. Ergonomia 2: O ambiente físico de trabalho, a produtividade e a qualidade de vida em odontologia. São Paulo: Pancast Editora, 1993.

CASTRO, S. L., FIGLIOLI, M. D. Ergonomia aplicada a dentística. Avaliação da postura e posições de trabalho do Cirurgião Dentista destro e da auxiliar odontológica em procedimentos restauradores. Jornal Brasileiro de Clínica Odontológica Integrada, v.3 n.14, p.56-62, 1999.

FIALHO, F. A. P.; SANTOS, N. Manual de análise ergonômica do trabalho. Curitiba: Gênesis, 1995.

FINKBEINER, B.L. Four Handed Dentistry Revisited. The Journal of Contemporary Dental Practice, v. 1, n.4, Fall Issue, 2000.

GUERIN, F. Compreender o trabalho humano para depois transformá-lo: a prática da ergonomia. São Paulo: Editor Atlas, 2001. 
GRANDJEAN, E. Manual de Ergonomia: Adaptando o trabalho ao homem. Porto Alegre: Editora Artes Médicas Sul LTDA, 1998.

IIDA, ITIRO. - Ergonomia: Projeto e produção - 2 edição rev. e ampl. - São Paulo: Edgard Blucher, 2005.

IEA International Ergonomics Association. What is ergonomics.Disponível em: <http://www.iea.cc/browse. php?contID=what_is_ergonomics>. Acesso em: 11 fev. 2015 .

MORAES, A.; MONT’ ALVÃO, C. Ergonomia: conceitos e aplicações. Rio de Janeiro: 2AB, 1998.

MORAES, A.; SOARES, M. M.. Ergonomia no Brasil e no mundo: um quadro, uma fotografia. Rio de Janeiro: ABERGO/UNIVERTA, 1989.

MTE - Ministério do Trabalho e Emprego. Normas Regulamentadoras - Segurança e Saúde do Trabalho, disponíveis em: 〈http://portal.mte.gov.br/legislacao/normas-regulamentadoras-1.htm〉. Acesso em: 12 fev. 2015.

NOGUEIRA, D. P. Riscos ocupacionais de dentistas e sua prevenção. Rev. Bras. Saúde Ocup.; 41(11):14-6, 1983.

PIETROBON, L.; REGIS FILHO, G. I. Cifoescoliose em cirurgiões-dentistas: uma abordagem ergonômica. XXVI ENEGEP, Fortaleza, CE, Brasil, 9 a 11 de Outubro de 2006. In: Anais..., Fortaleza: 2006.

PORTO, F. A. O Consultório Odontológico. São Carlos: Scritti, 1994.

RIO, L. M. S. P.; RIO, R. P. Manual de Ergonomia Odontológica. $1^{\text {a }}$ ed. Belo Horizonte: Conselho Regional de Odontologia de Minas Gerais, 2000.

VIDAL, Mario César. Guia para Análise Ergonômica do Trabalho (AET) na Empresa: uma metodologia realista ordenada e sistemática. Rio de Janeiro: Virtual Cientifica, 2003.

\section{Dados dos Autores:}

Nome completo: Ari de Oliveira Maciel Junior

Filiação Institucional: Universidade Tecnológica Federal do Paraná Departamento Construção Civil DACOC (Coordenação do Curso: Dr. ${ }^{a}$ Clarice Farian de Lemos).

Função ou cargo ocupado: Aluno pós-graduação,especialização em Engenharia de Produção da Universidade Tecnológica Federal do Paraná (Orientador: Prof. Dr. Rodrigo Eduardo Catai).

Endereço instituição: Av. Sete de Setembro, 3165 - Rebouças CEP 80230-901 - Curitiba-PR.

Nome completo: Rodrigo Eduardo Catai

Filiação Institucional: Universidade Tecnológica Federal do Paraná

Departamento: Construção Civil

Função ou cargo ocupado: Professor.

Endereço instituição: Av. Sete de Setembro, 3165 - Rebouças CEP 80230-901 - Curitiba - PR.

Submetidoem: 15-06-2015

Aceitoem: 14-09-2015 